\title{
MECHANICAL PROPERTIES OF CORRODED HIGH PERFORMANCE STEEL SPECIMENS BASED ON 3D SCANNING
}

\author{
Lin-fa Xiao ${ }^{1}$, Jian-xin Peng ${ }^{1, *}$, Jian-ren Zhang ${ }^{1}$ and Chun-sheng Cai ${ }^{2}$ \\ ${ }^{1}$ School of Civil Engineering, Changsha University of Science and Technology, Changsha, China \\ ${ }^{2}$ Department of Civil and Environmental Engineering, Louisiana State University, USA \\ *(Corresponding author: E-mail: jianxin_peng78@163.com)
}

\section{A B S T RACT}

An experimental study was performed to investigate the impact of corrosion on the mechanical properties of high performance steel (HPS) specimens. Fifteen HPS specimens were designed and subjected to electrochemically accelerated corrosion. The geometric features of the specimens were quantified by using 3D scanning technology. Then, tensile tests were employed to study the mechanical properties of the corroded HPS specimens. The relationship between the mechanical properties of the corroded HPS specimens and corrosion damage was discussed in detail. Meanwhile, a three-stage constitutive model was proposed to evaluate the mechanical behaviors of the degraded HPS specimens. Finally, a finite element model based on 3D scanning technology was developed and verified to investigate the stress distribution and failure of the tensile specimens. Results show that the maximum cross-sectional loss ratio $\rho_{A}$ is a suitable parameter for describing the mechanical properties of the degraded HPS specimens. The failure modes of the HPS specimens gradually vary from ductile to brittle as $\rho_{A}$ varies from $0 \%$ to $50.28 \%$. It is found that the yield or ultimate load decreases linearly as the $\rho_{A}$.increases. The corrosion-induced ductility reduction has an exponential relationship with $\rho_{A}$. A comparison between the numerical results and experimental results shows that the proposed three-stage constitutive model is rational.

\section{ART I C LE H I S T O R Y}

$\begin{array}{ll}\text { Received: } & \text { 09 January } 2018 \\ \text { Revised: } & \text { 28 June } 2018 \\ \text { Accepted: } & \text { 18 July } 2018\end{array}$

\section{K E Y W O R D S}

\author{
High performance steel; \\ Mechanical property; \\ 3D scanning technology; \\ Corrosion;
}

FEM

\section{Copyright (C) 2019 by The Hong Kong Institute of Steel Construction. All rights reserved.}

\section{Introduction}

High Performance steel (HPS) is defined differently in each country. In the United States, for example, it is defined as steel with high strength, good toughness and good weldability, whereas in Europe and China it is defined as having one of the excellent properties, such as high strength steel. In this paper HPS represents the high strength steel. Compared with ordinary steel, HPS is favored by civil engineers for its higher strength, better ductility, and lower thickness effect. At present, HPS has been widely adopted in many engineering structures, such as the Minato Ohashi Bridge [1] and the Millau Bridge [2]. Because of its good structural performance and economic benefits, the research and application of HPS have become the hot topics in the area of steel structures. For example, Shi et al. [3] conducted cyclic loading tests on HPS, and analyzed its constitutive model and structural reaction. Wang et al. [4] carried out bending tests on HPS485W I-beam, and concluded that the buckling strength and lateral support of the web played a major role in the failure modes of I-beams subjected to bending. Kayser et al. [5] found that the yield strength and ultimate strength depend on the thickness and direction of the sample, and its good toughness and strength is suitable for structural seismic resistance. Considering the influencing factors of repeated loading, damage, residual stress, low-cyclic performance, and hysteretic behavior, Li et al. [6-7] studied the compressive performance and bending capacity of Q460 high strength steel columns. Based on the experimental and numerical results, Lee et al. [8] evaluated the flexural ductility of the negative bending moment of a $690 \mathrm{MPa}$ I-beam. These works mainly focus on the mechanical behavior of non-corroded HPS specimens or structures.

Although paint coating is often used to prevent steel structures from being corroded, for steel members located in harsh environments such as coastal areas, or due to deicing salts and chemical plants, corrosion occurs inevitably as the spalling of the coating [9]. This may lead to decrease of cross-section dimensions, change the slenderness ratio, cause stress concentration, and consequently reduce the bearing capacity of the structures [10]. Therefore, corrosion is a major threat to their structural durability and safety performance Many efforts have been directed to study the mechanical behavior of ordinary corroded steel specimens or structures. For example, Khedmati et al. [11] investigated the strength and failure behavior of randomly corroded steel specimens subjected to in-plane compression load, and found that the reduction of the buckling strength was greater than that of the ultimate strength. Nakai et al. [12] carried out tensile and compressive buckling tests of steel specimens subject to pitting corrosion, and suggested that pitting corrosion results in a significant reduction in tensile strength and buckling strength of steel specimens. Beaulieu et al. [13] found that the compressive bearing capacity of angle steel was reduced by corrosion, and a residual compression capacity model was proposed based on the residual average thickness. With the interaction of corrosion, aging, load and other unfavorable factors, deterioration of the structural performance would be aggravated, and the structure eventually need to be strengthened or rebuilt. At present, these previous works [14-16] have focused on mechanical behaviors of non-corroded HPS components and related connections, and few studies have been directed on the degradation characteristics of corroded HPS specimens or structures. The existing durability design method of HPS is based on the research results of ordinary steels, which may lead to unpredictable consequences due to the different mechanical characteristics of HPS. Therefore, the mechanical behavior of corroded HPS specimens or structures needs to be researched.

A suitable corrosion parameter should be determined to describe the corrosion level. In the previous studies, the mass loss rate, the average sectional loss rate, and the average corrosion penetration depth were often used to characterize the corrosion level of structural components [17-20]. These parameters represent the average corrosion degree of specimens. However, the corrosion damage of steel is a process with randomness and spatial variability, which leads to uneven cross-sectional loss along the length of the structure component. As a consequence, the failure condition of specimens with non-uniform corrosion cannot be accurately described by average corrosion levels. The existing researches [21-23] showed that the corrosion degree can be better evaluated by using the maximum cross-sectional loss ratio through the calculation of the minimum residual area. The traditional method for determining the residual area was first to divide the specimen into several parts, and then to weigh them [24]. This method can obtain the residual area, but the experimental process was time-consuming and the results were rough. These shortcomings hindered the further application of the traditional measurement methods to the geometric modeling of corroded components due to its complex corrosion surfaces.

In this study, a new technique, termed as 3D optical scanning, is employed to resolve the aforementioned problems. The 3D scanning has the advantages of high precision, portability, and high efficiency. Additionally, it can automatically reconstruct the shape of the specimen and neglect the influence of the surface complexity. There were some efforts on this application to the corrosion characteristics and reliability assessment of corroded structures. Kashani et al. [25] obtained the geometrical characteristics of corroded steel bars based on 3D scanning, and proposed probability distribution models of area pitting coefficient, residual second moment of area coefficient, and load eccentricity coefficient. Fernandez et al. [26] investigated the influence of pitting on the failure process and mechanical properties according to scanning results, and a 3D finite element model for simulating the pitting was presented and verified. Zhang et al. [27] carried out the time-dependent reliability analysis of corroded RC beams on the basis of 3D geometric models. In this study, 3D scanning technique was employed to determine the minimum residual area of corroded HPS specimens.

The proposed study aims to explore the impacts of corrosion on the mechanical properties of corroded HPS specimens. Fifteen HPS specimens were obtained by using electrochemical accelerated corrosion. The geometric 
features of the specimens were quantified by using 3D scanning technology, and the maximum cross-sectional loss ratio $\rho_{A}$ was identified to evaluate corrosion damage. Then, the degradation of mechanical properties affected by corrosion was discussed after static tensile tests. Further, a three-stage constitutive model for the corroded HPS specimens was proposed and validated. Finally, a finite element model was established and verified to investigate the stress distribution and failure behavior.

\section{Experimental program}

\subsection{Specimens details}

In this study, fifteen 460D steel specimens with a yield strength of $460 \mathrm{MPa}$ and dimensions of $220 \mathrm{~mm} \times 30 \mathrm{~mm} \times 8 \mathrm{~mm}$ (length $\times$ width $\times$ height $)$ were designed and fabricated according to the standard of GB/T 228-2002 [28]. Three of the specimens were the non-corroded control specimens. The others represent specimens with different corrosion degrees, as summarized in Table 1. The chemical composition of the specimens is shown in Table 2. The specimen details are shown in Fig. 1.

\subsection{Accelerated corrosion process}

In this research, the mass loss rate was used to control the corrosion time. To accelerate the corrosion process, an electrochemical accelerated corrosion method was employed. As illustrated in Fig. 2, twelve steel specimens, connected in series with copper wires at the central position, were placed in the plastic groove with a $5 \% \mathrm{NaCl}$ solution. To prevent corrosion of the gripped end, epoxy resin and waterproof tape were used to wrap it tightly. The specimens were linked to the positive end as the anode. One stainless steel plate, as the cathode, was connected to the negative end of the DC power supply providing a stable electric current of $1000 \mathrm{~mA}$. Under the action of current, the anode undergoes an oxidation reaction, and the $\mathrm{Fe} 2+$ produced on the surface of the steel plate is continuously lost. Meanwhile, the cathode undergoes a reduction reaction. As a result, electrochemical corrosion occurs, and the corrosion rate can be controlled by adjusting the applied electric current. In order to achieve the designed degree of corrosion, Faraday's law was employed to estimate the duration of the applied corrosion current [29]. After reaching a specified corrosion level, the corroded steel specimens were taken out from the plastic tank and cleaned according to the procedure described in ASTM G1-03 [30], and then the mass loss rate was calculated and listed in Table 3.

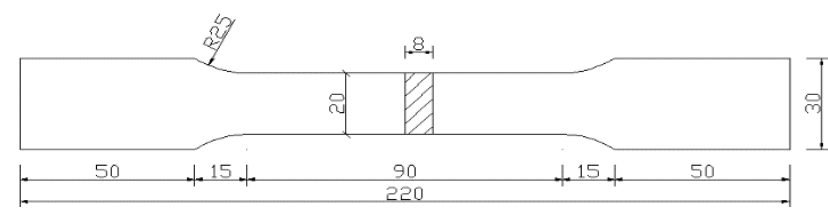

Fig. 1 Dimensions of specimen

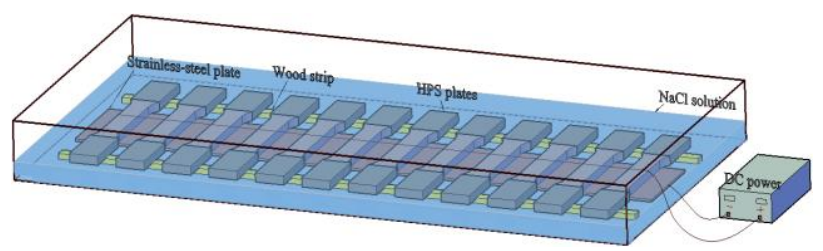

Fig. 2 Schematic diagram of accelerated corrosion test

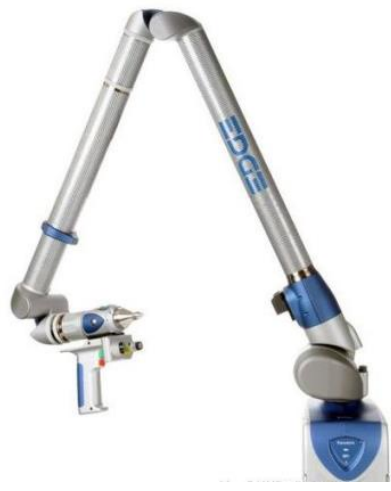

Fig. 3 A 3D scanning device

Table 1

Summary of HPS specimens

\begin{tabular}{ccc}
\hline Specimen & Corrosion & Quantity \\
\hline D0-i & 0 & 3 \\
D5-i & $5 \%$ & 3 \\
D10-i & $10 \%$ & 3 \\
D15-i & $15 \%$ & 3 \\
D20-i & $20 \%$ & 3 \\
\hline
\end{tabular}

(Notes: i represents the sequence number of specimens $(i=1,2,3)$.)

Table 2

Chemical composition of steel specimens

\begin{tabular}{ccccccccccc}
\hline Material & $\mathrm{C}$ & $\mathrm{Si}$ & $\mathrm{Mn}$ & $\mathrm{P}$ & $\mathrm{S}$ & $\mathrm{Ceq}$ & $\mathrm{Cr}$ & $\mathrm{Nb}$ & $\mathrm{Ni}$ & $\mathrm{Cu}$ \\
\hline Q460D & 0.16 & 0.21 & 1.48 & 0.014 & 0.005 & 0.42 & 0.04 & 0.19 & 0.01 & 0.01 \\
\hline
\end{tabular}

Table 3

Mechanical parameters of corroded HPS specimens

\begin{tabular}{|c|c|c|c|c|c|c|c|}
\hline No. & $\rho_{m}$ & $\rho_{A}$ & $A_{\min }\left(m m^{2}\right)$ & $E_{c}\left(\times 10^{5}\right)\left(\mathrm{N} / \mathrm{mm}^{2}\right)$ & $F_{y}(\mathrm{kN})$ & $F_{u}(\mathrm{kN})$ & $\delta_{u}(\mathrm{~mm})$ \\
\hline A0avg & 0 & 0 & 160 & 1.59 & 91.01 & 99.59 & 5.29 \\
\hline D5-1 & $5.97 \%$ & $19.82 \%$ & 128.3 & 0.82 & 66.43 & 85.51 & 4.92 \\
\hline D5-2 & $8.14 \%$ & $22.10 \%$ & 124.6 & 1.23 & 62.39 & 83.76 & 4.66 \\
\hline D5-3 & $8.14 \%$ & $23.40 \%$ & 122.6 & 1.27 & 65.04 & 86.23 & 4.36 \\
\hline D10-1 & $10.36 \%$ & $26.78 \%$ & 117.1 & 2.02 & 59.55 & 79.05 & 4.89 \\
\hline D10-2 & $10.65 \%$ & $26.89 \%$ & 117 & 1.62 & 60.70 & 81.11 & 4.76 \\
\hline D10-3 & $10.76 \%$ & $26.96 \%$ & 116.9 & 1.95 & 59.73 & 79.97 & 4.78 \\
\hline D15-1 & $14.37 \%$ & $33.68 \%$ & 106.1 & 1.12 & 53.49 & 75.18 & 4.52 \\
\hline D15-2 & $19.48 \%$ & $43.45 \%$ & 90.48 & 1.42 & 46.28 & 65.17 & 4.49 \\
\hline D15-3 & $20.71 \%$ & $43.69 \%$ & 90.09 & 1.16 & 45.94 & 62.34 & 3.83 \\
\hline D20-1 & $20.97 \%$ & $44.97 \%$ & 88.05 & 1.49 & 44.42 & 62.46 & 3.37 \\
\hline D20-2 & $26.37 \%$ & $50.28 \%$ & 79.95 & 0.65 & 40.00 & 56.25 & 4.11 \\
\hline D20-3 & $28.51 \%$ & $55.75 \%$ & 71.8 & 0.74 & 35.95 & 50.51 & 3.06 \\
\hline
\end{tabular}

where $\rho_{m}$ is the mass loss rate; $\rho_{A}$ is the maximum cross-sectional loss ratio; $A_{\min }$ is the minimum residual area; $E_{c}$ is the elastic modulus; $F_{y}$ is the

yield load; $F_{u}$ is the ultimate load; and $\delta_{u}$ is the elongation at the ultimate load. 


\subsection{D laser scanning of steel specimens}

After cleaning, a 3D scanning device (see Fig. 3) with accuracy of $29 \mu \mathrm{m}$ was employed to reconstruct the geometric model of the corroded specimens. Optimized operations, such as filtering and noise processing, were performed to obtain more realistic point cloud data by using Geomagic Control software. A curved surfaces model was generated based on the point cloud data. Finally, the geometrical dimensions of corroded specimens can be determined. All the corroded steel specimens were treated with $3 \mathrm{D}$ scanning, and some specimens were extracted to compare the difference between the real shape and the 3D geometry model. As shown in Fig. 4, 3D laser scanning can well reflect the surface morphology of corroded steel specimens.

\subsection{Monotonic test}

All the specimens were tested on the microcomputer controlled electro-hydraulic servo universal testing machine, as shown in Fig. 5. The extensometer was placed within the gauge range to measure the elongation of the specimen [31]. The tensile test was controlled by displacement until the specimens failed. The load displacement curve can be automatically recorded by the computer, and the characteristic mechanical parameters, such as yield load, ultimate load, and elongation can be conveniently determined. The tensile test results were shown in Table 3 .

\section{Experimental results and discussion}

\subsection{Maximum cross-sectional loss ratio}

To visually appreciate the geometrical characteristics of the corroded HPS specimens, the scanned images of steel specimens with different corrosion levels are showed in Fig. 6. As Fig. 6 shows, the cross-sectional losses of the steel specimens are not evenly distributed both around the width and the length of the specimen. The surface of specimen D5-1 with low corrosion damage is relatively flat and has small pits. The cross-section sizes of specimens reduce gradually as corrosion degree increases, and the large corrosion pits even disappeared for seriously corroded specimen D20-3. This phenomenon is inconsistent with corrosion behavior of steel bars. This is because the diffusion process of chloride ions in each direction for steel bars in concrete is variable [32-33]. Fig. 7 presents the cross-sectional area of the corresponding specimens. The cross-section profile of specimens varies from flat to irregular shape with the increasing corrosion loss. Therefore, the weakest cross section position is unknown and is difficult to determine through ordinary methods.

In addition, the residual sectional area with a spacing $3 \mathrm{~mm}$ along the length of specimens was obtained with Geomagic Control software. The discreteness of the cross-sectional area is characterized by Discrete Coefficient (CV). Fig. 8 plots the variation of cross-sectional areas of specimens. As Fig. 8 shows, the cross-sectional area of steel specimens decreases gradually from $130 \mathrm{~mm}^{2}$ to $80 \mathrm{~mm}^{2}$ as the corrosion rate increases from $19.82 \%$ to $50.28 \%$. The CV increases as corrosion gradually becomes serious. For example, the increase of CV in specimen D20-2 is 6.03 times that of specimen D5-1. This shows that the cross-sectional distribution is very uneven when a structure is corroded seriously.

Fig. 9 shows the cross-sectional area distribution and fracture position of the corroded HPS specimens. As Fig. 9 shows, the areas of steel specimens randomly change along the longitudinal direction, which indicates the randomness of the corrosion damage. The minimum cross-sectional area of the corroded specimen is very close to the fracture position, which suggests that it is reasonable to characterize mechanical properties of the corroded steel specimens with the maximum cross-sectional loss ratio [34]. This is different from some researches [35] taking the minimum thickness or maximum corrosion depth as the corrosion parameters, because the section loss of steel specimens includes the loss rates in both the width direction and the depth direction in this test. In addition, the assumption that the mass loss rate is used to characterize the corrosion degree can be ruled out by considering that slight corrosion occurs at the clamping ends of specimens. Therefore, the maximum cross-sectional loss ratio $\rho_{A}$, as listed in Table 3 , is used to analyze the mechanical properties of the corroded HPS specimens in this study.

\subsection{Fracture characteristics}

The fracture characteristics of specimens D0-1, D5-3, D10-3, and D20-2 are shown in Fig. 10. The fracture shape of the non-corroded specimen D0-1 is crescent. Obvious dimples and necking are observed on the fracture section, which can be considered as a ductile failure. As the corrosion degree

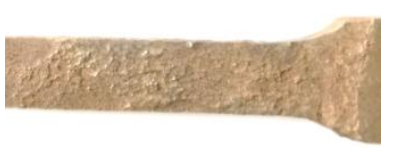

(a) test sample

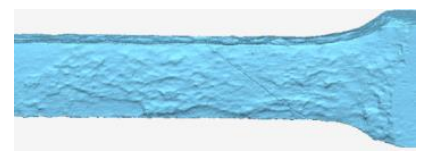

(b) scanned sample
Fig. 4 Comparison of surface morphology

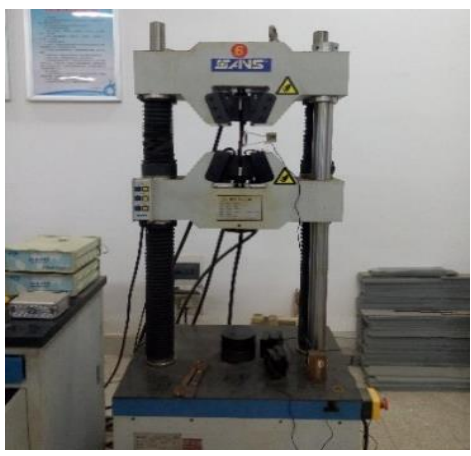

Fig. 5 Universal testing machine

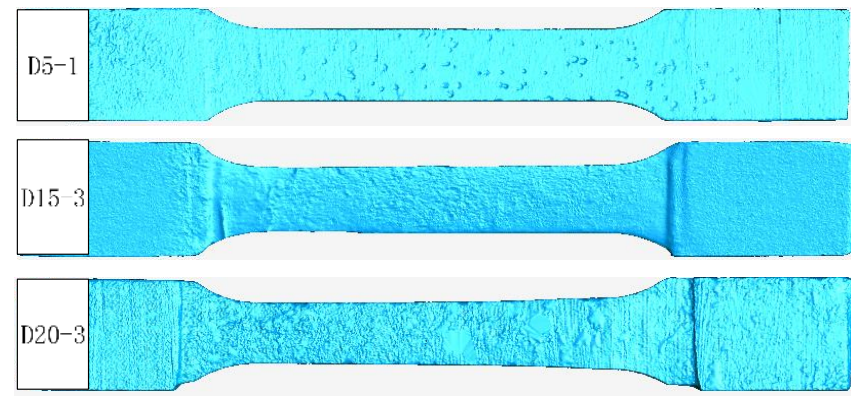

Fig. 6 3D scanning morphologies of steel specimens

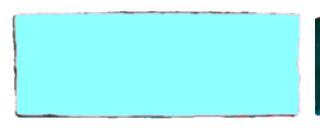

D5-1

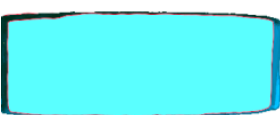

D15-3

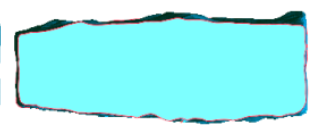

D20-3
Fig. 7 Cross sectional scanning morphology of steel specimens

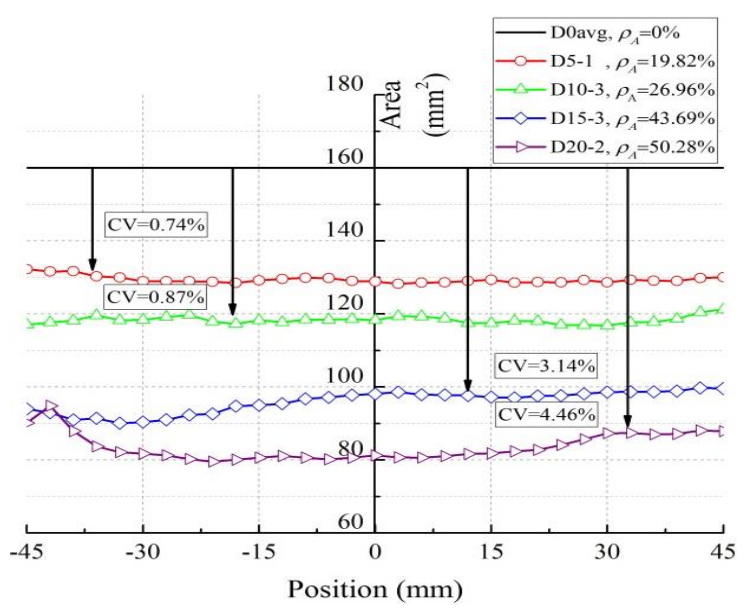

Fig. 8 Longitudinal distribution of cross section area

increases, the fracture features of the corroded specimens D5-3 and D10-3 change from the crescent to regular shape, while the fracture condition of specimens D20-2 subjected to severe corrosion is irregular. The dimples 
gradually disappear, and then the failure behavior varies from ductile to brittle. This implies that corrosion gradually transforms the failure mode from the ductile failure to brittle failure. This is probably due to the impact of both corrosion pits and the irregular shape of cross-section, which makes the fracture surface become a high stress zone. When the corrosion becomes more serious, this section may reach the ultimate stress earlier. The necking would appear more rapidly and the specimen fails earlier.
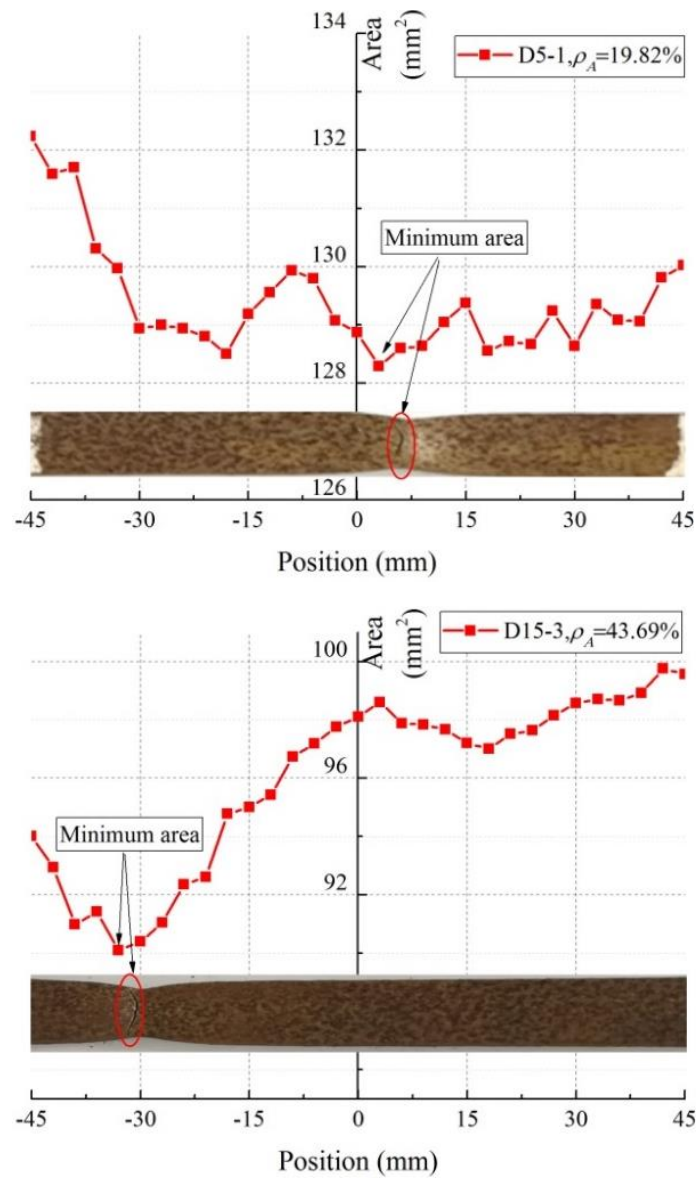
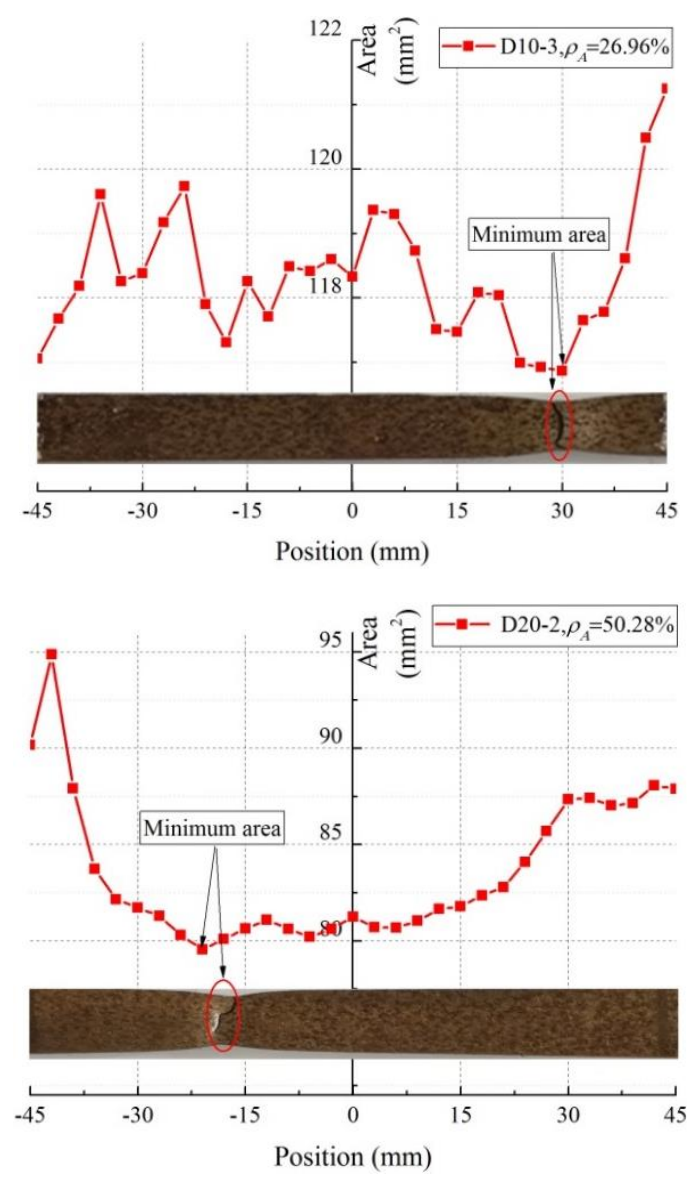

Fig. 9 Representative area-position diagram
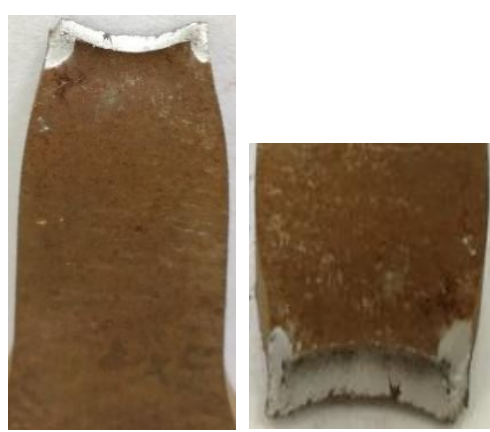

(a) D0-1

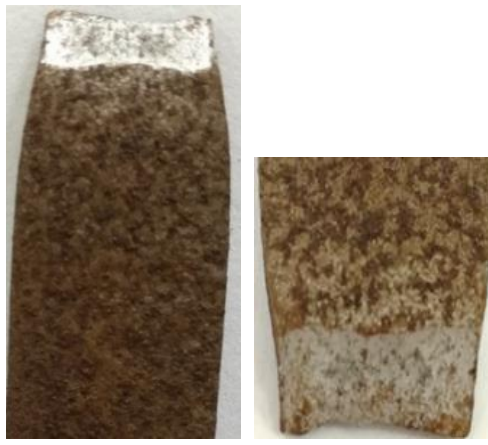

(c) D10-3

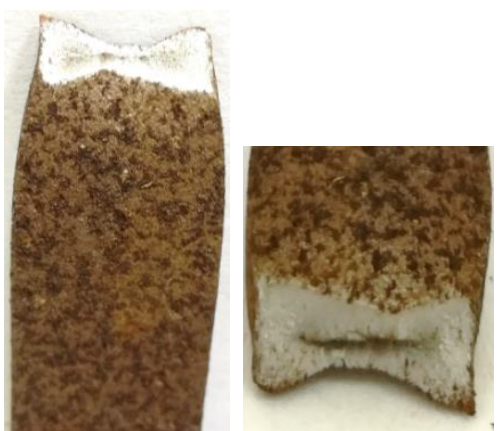

(b D5-3
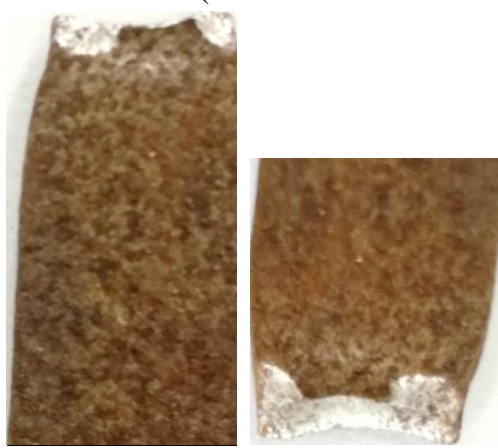

(d) D20-2

Fig. 10 Fracture morphologies 


\subsection{Mechanical behaviors of HPS specimens}

\subsubsection{Load-elongation curves}

Fig. 11 presents the load-elongation curves of some representative specimens after static tensile tests. As Fig. 11 shows, the load-elongation results are quite different as a result of the different degrees of corrosion damage. The yield load of specimen D20-3 with a $55.75 \%$ corrosion rate is $60.5 \%$ lower than that of the control specimen D0avg, and the ultimate load is decreased by $49.3 \%$. There are obvious yield plateau and necking stage before the fracture failure for specimens D0avg and D5-2. When the $\rho_{A}$ reaches $26.78 \%$, the necking phenomenon of specimen D10-1 disappears and the yield plateau shortens obviously. For severe corrosion specimens D15-3 and D20-3, an obvious yield plateau cannot be observed. Therefore, corrosion has an adverse impact on the strength and deformation of corroded HPS specimens.

Results are presented in Fig. 12 and Fig. 13 in terms of $\rho_{A}$ versus yield load $F_{y}$ and the ultimate load $F_{u}$ and $\rho_{A}$ versus the relative elongation, respectively. The relative elongation $\delta_{r}$ is defined as the ratio of elongation of corroded specimens and that of the control specimens. As Fig. 12 shows, both $F_{y}$ and $F_{u}$ decrease linearly with the increase of the maximum cross-sectional loss ratio $\rho_{A}$. The load degradation of $F_{y}$ is faster than that of $F_{u}$, which indicates that corrosion has a more adverse impacts on the yield load degradation. The high R-squared values further confirm the rationality of applying the maximum cross-sectional loss ratio to predict the degradation of mechanical properties. As showed in Fig. 13, the relative elongation $\delta_{r}$ decreases gradually as the maximum cross-sectional loss ratio $\rho_{A}$ increases. Through regression analysis with Origin software, a parabolic attenuation model is considered to be a good agreement with the tested data. The degradation of $\delta_{r}$ caused by corrosion (lower than 25\%) is relatively small. With further corrosion, it drops sharply. This can be explained that the cross section of the corroded steel specimens is very unevenly distributed along the axial direction, and the phenomenon of sectional eccentricity and stress concentration are ubiquitous, resulting in complex multi-axial stress under axial tension. The minimum section would reach the ultimate stress in advance, then the necking behavior occurs prematurely, and finally the elongation at ultimate load decreases. When the degree of corrosion exceeds a critical value, the phenomenon is prominent.

\subsubsection{Elastic modulus}

Zhang et al. [36] found that the elastic modulus was not affected by corrosion for ordinary corroded steel specimens. In order to understand how the corrosion influences the elastic modulus of the HPS specimens, the relation between the elastic modulus and the maximum cross-sectional loss ratio is analyzed as shown in Fig. 14. With the increase of $\rho_{A}$, the variation pattern of the elastic modulus changes insignificantly, and it fluctuates near a certain value. Therefore, we can assume the $\rho_{A}$ does not affect the elastic modulus. The fluctuation of elastic modulus is mainly due to the variation of the different specimens and test error. This phenomenon is similar to that of corroded ordinary steel and corroded steel bars [36]. Therefore, the effect of corrosion on the elastic modulus is ignored.

\subsubsection{Yield and ultimate strengths}

In this paper, relative nominal yield strength $R_{n y}$, relative nominal ultimate strength $R_{n u}$, relative real yield strength $R_{r y}$ and relative real ultimate strength $R_{r u}$ are introduced to characterize the strength properties [37]. Relative strength is defined as the ratio of nominal or real strength of corroded specimens and that of non-corroded ones $f_{0}$. The nominal yield strength $f_{n y}$ or the nominal ultimate strength $f_{n u}$ is the ratio of the yield or ultimate load and the minimum residual area, respectively. Similarly, the real yield strength $f_{r y}$ or ultimate strength $f_{r u}$ is the ratio of the yield or ultimate load and the real cross-sectional area, respectively.

Fig. 15 shows the variation of the yield strength and ultimate strength with the corrosion rate. As shown in Fig.15, the nominal and real yield strength decrease almost by following the same path, while the nominal and real ultimate strength increase with the maximum cross-sectional loss ratio. This is due to the large stiffness of the HPS specimens and the small reduction of the cross-sectional area under the yield load, which would not cause obvious decline of $f_{r y}$ and $f_{n y}$. However, $f_{r u}$ and $f_{n u}$ are obviously different as the area has changed obviously during the tensile test. Fig. 16 presents the relative nominal and real yield strength, and the relative nominal and real ultimate strength are plotted in Fig. 17. It could be noticed that the relative nominal or real yield strength decreases exponentially with the increase of the maximum cross-sectional loss ratio, while the increase of the relative nominal or real ultimate strength conforms to a similar parabolic law. This provides a new path to determine the real yield strength and the real ultimate strength of the corroded HPS specimens.

\subsubsection{Ductility}

Ductility reflects the plastic deformation ability before failure. In order to take into account the impacts of corrosion on both the structural strength and strain, the reduction of energy absorption [38] is introduced to characterize the ductility of the corroded HPS specimens. It could be described as

$$
R_{e}=\frac{e_{c}}{e_{0}}
$$

where $R_{e}$ is the reduction of energy absorption, $e_{c}$ and $e_{0}$ are the total energy value of corroded specimens and the control specimens, respectively. The energy is determined by integrating the area under the nominal stress-strain curve.

Fig. 18 shows the impact of corrosion damage on the ductility of the HPS specimens characterized by $R_{e}$. As shown in Fig. 18, $R_{e}$ decreases rapidly when $\rho_{A}$ is less than $32 \%$, and then $R_{e}$ reduces slowly with the increase of $\rho_{A}$. The deterioration characteristic of $R_{e}$ is well fitted by the exponential function. The law of energy attenuation is similar to the results of corroded steel rebar carried out by other researchers [39].

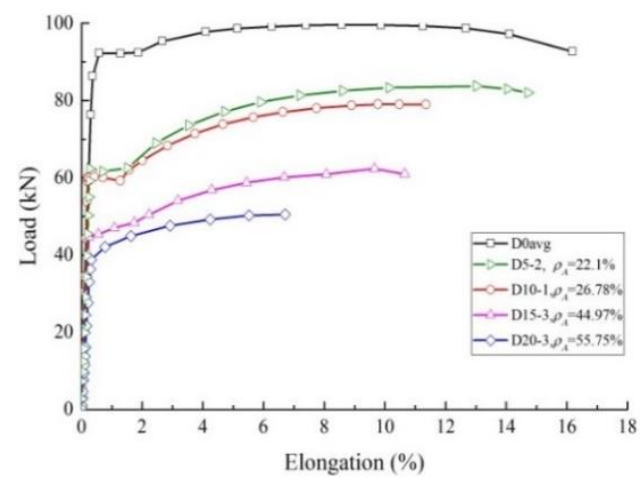

Fig. 11 Load-elongation curves

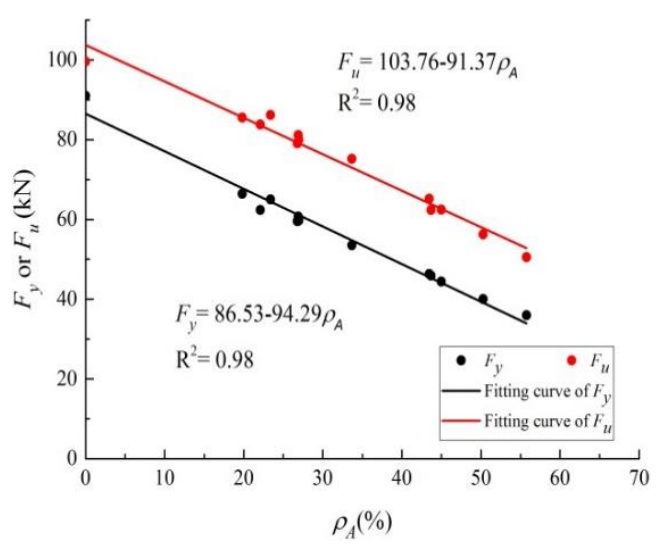

Fig. 12 Effect of corrosion on yield and ultimate load

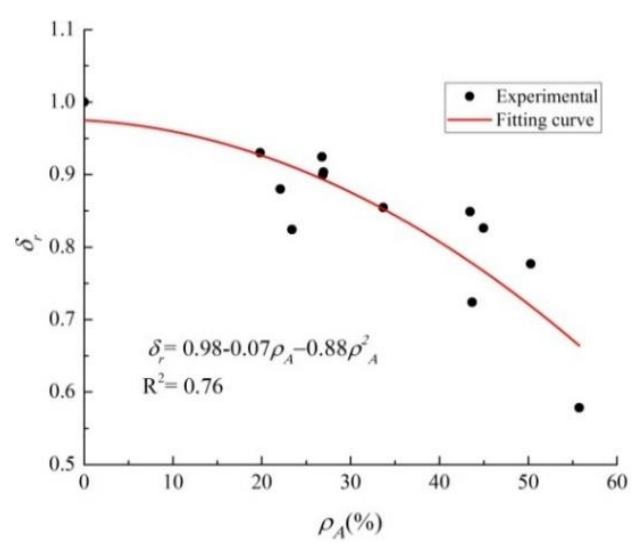

Fig. 13 Effect of corrosion on relative ultimate elongation 


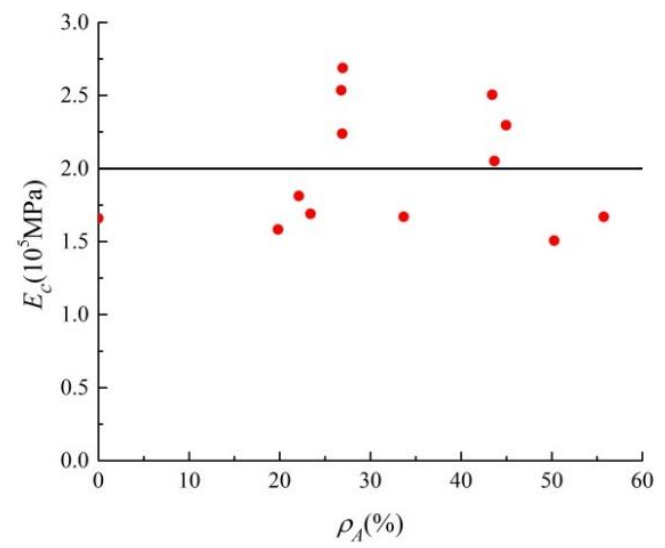

Fig. 14 Effect of corrosion on elastic modulus

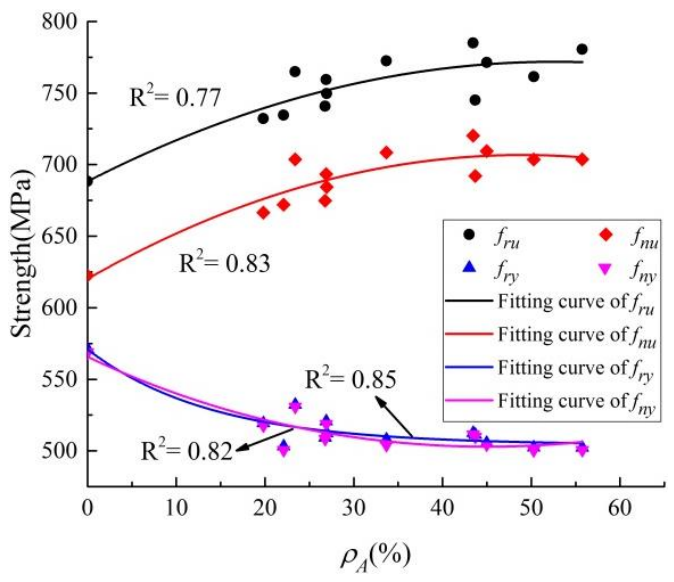

Fig. 15 Effect of corrosion on yield strength and ultimate strength

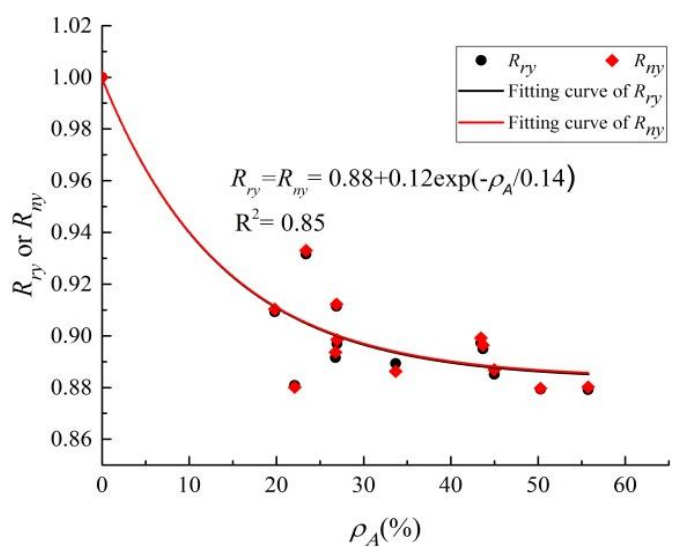

Fig. 16 Effect of corrosion on relative nominal or real yield strength

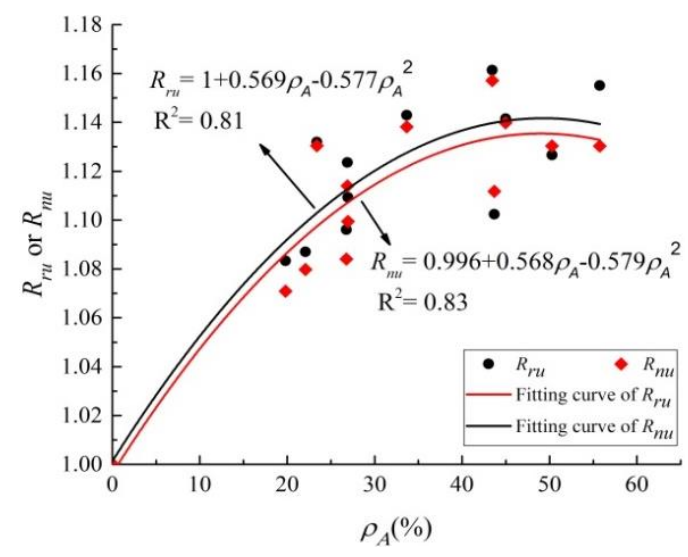

Fig. 17 Effect of corrosion on relative nominal or real ultimate strength

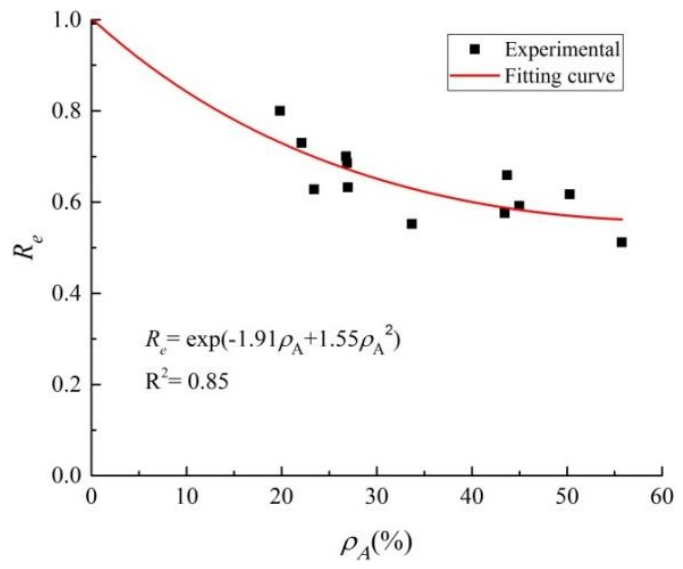

Fig. 18 Effect of corrosion on ductility

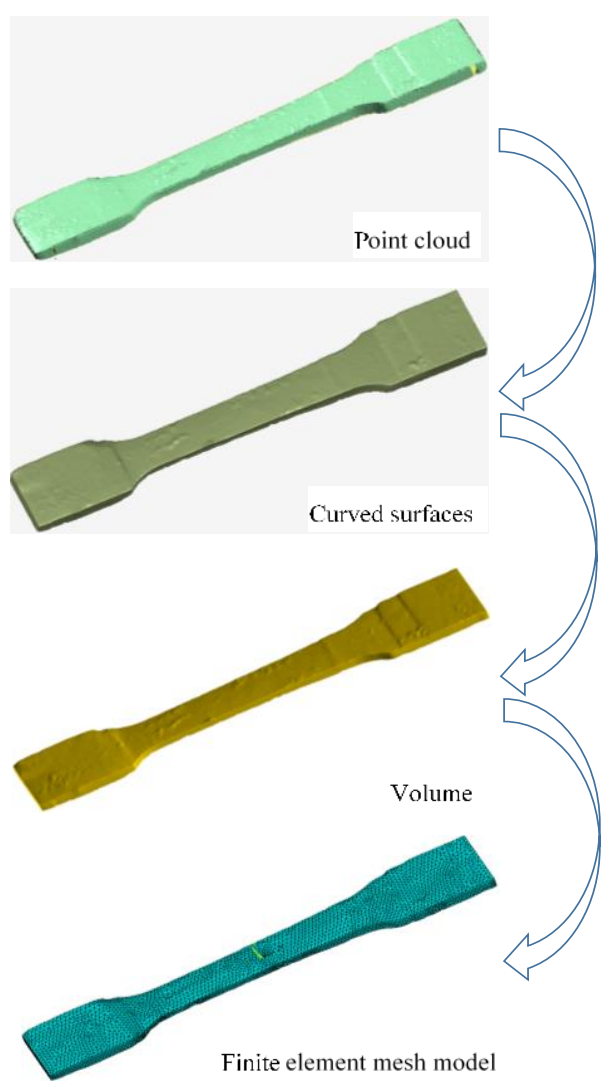

Fig. 19 Establishment process of 3D finite element model

\subsection{Constitutive model of corroded HPS specimen}

Some related studies $[34,40]$ have proposed the constitutive model of corroded steel specimens, but some parameters are not clearly identified, such as shape parameter. Therefore, a simplified three-stage constitutive model of HPS specimens is proposed in this study, and the descending segment is ignored for its shorter duration. The mathematical expression is shown as:

$\sigma=\left\{\begin{array}{c}E_{c} \varepsilon, 0 \leq \varepsilon \leq \varepsilon_{y} \\ f_{n y}, \varepsilon_{y}<\varepsilon \leq \varepsilon_{h} \\ f_{n y}+\left(f_{n u}-f_{n y}\right)\left(\frac{\varepsilon-\varepsilon_{h}}{\varepsilon_{u}-\varepsilon_{h}}\right), \varepsilon_{h}<\varepsilon \leq \varepsilon_{u}\end{array}\right.$

where $E_{c}$ is the modulus elasticity of corroded specimens, $E_{c}=E_{0} ; f_{n y}$ is the nominal yield strength, $f_{n y}=R_{n y} f_{0} ; f_{n u}$ is the nominal ultimate strength, $f_{n u}=R_{n u} f_{0} ; \varepsilon_{y}$ is the yield strain, $\varepsilon_{y}=f_{n y} / E_{c} ; \varepsilon_{u}$ is the ultimate strain, calculated by $\delta_{r}$; and $\varepsilon_{h}$ is the hardening strain. According to the results of tensile test, $\varepsilon_{h}$ is expressed as:

$\varepsilon_{h}=0.019-0.017 \rho_{A}, R^{2}=0.76$ 


\section{Numerical analysis}

\subsection{Numerical model}

Finite element models are established to further investigate the strength, stress distribution, and fracture behaviors of the corroded HPS specimens. The real geometry model of the corroded specimen is applied to develop the numerical model. The corrosion morphology of the specimen can be truly reflected in the finite element model. Fig. 19 depicts the main process from the point cloud file to the final solid finite element mesh model. The point cloud data of the corroded specimen is fitted to the curved surfaces after wrapping, repairing, and grid division by the Geomagic software. Subsequently, the IGES format file is exported to the ANSYS software for numerical simulation.

According to the above-mentioned experimental analysis, the modulus elasticity is determined by $E_{0}$, and the Poisson's ratio is set as 0.3 . The real constitutive model of the 460D steel specimen is derived from Eq. (2) in the numerical analysis [37], and characterized by the multi-linear kinematic hardening model. Von Mises yield criterion is adopted for the numerical analysis. An automatic incremental-iterative solution procedure is employed until the analysis reaches to the predetermined termination limit. Solid187 element and tetrahedral mesh are employed for the numerical analysis. A mesh width of $4 \mathrm{~mm}$ is used to achieve efficient computation time and high accuracy after an investigation of FEM mesh size. The displacement of the $\mathrm{X}, \mathrm{Y}$ and $\mathrm{Z}$ directions at the left end of the specimens is fixed, and only the $Y$ and $Z$ direction displacements of the other edge are fixed to simulate the actual tensile situation. The uniform incremental displacement is applied to the right end of the steel specimens.

\subsection{Numerical results}

\subsubsection{Comparison of load-elongation behavior}

Fig. 20 presents a comparison of numerical and experimental load-elongation behaviors of steel specimens subjected to corrosion. As Fig. 20 shows, the result of numerical simulation is slightly higher than the test one because of the more ideal constraints in the numerical model. In general, the numerical results are in good agreement with the experimental values. This indicates that the finite element model established in this paper based on 3D scanning can well describe the failure behavior of the corroded specimens.

\subsubsection{Stress distribution}

Fig. 21 presents the stress diagrams of specimen D20-3 at different time steps. As shown in the figure, the stress distribution is uneven. The stress in the $\mathrm{S}$ region is maximal, and reaches yielding strength firstly. The associated necking behavior is more obvious in this region. This can be attributed to the thinner cross-section area and the sharper corrosion pits in this section. The comprehensive effect would result in the formation of complex stresses, and lead to non-uniform deformation and premature yielding and failure.

Fig. 22 presents the stress distribution at the ultimate load of specimen D15-3. It can be seen that the stress from the numerical simulation is close to the real stress of the test. The maximum necking position of the numerical model is almost the same as the fracture position of the test one, which occurs at the minimum cross-section position. This indicates that the finite element model based on the 3D scanning can truly reflect the failure behavior of the corroded HPS

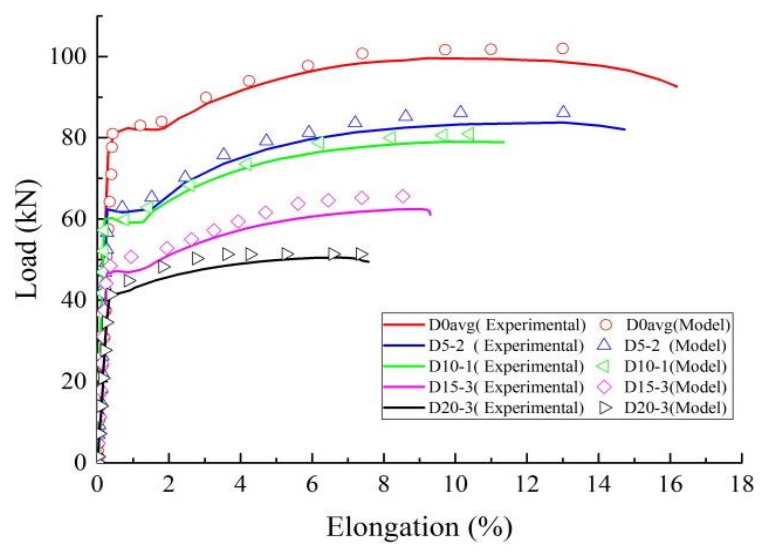

Fig. 20 Comparison of experimental and numerical load-elongation curves
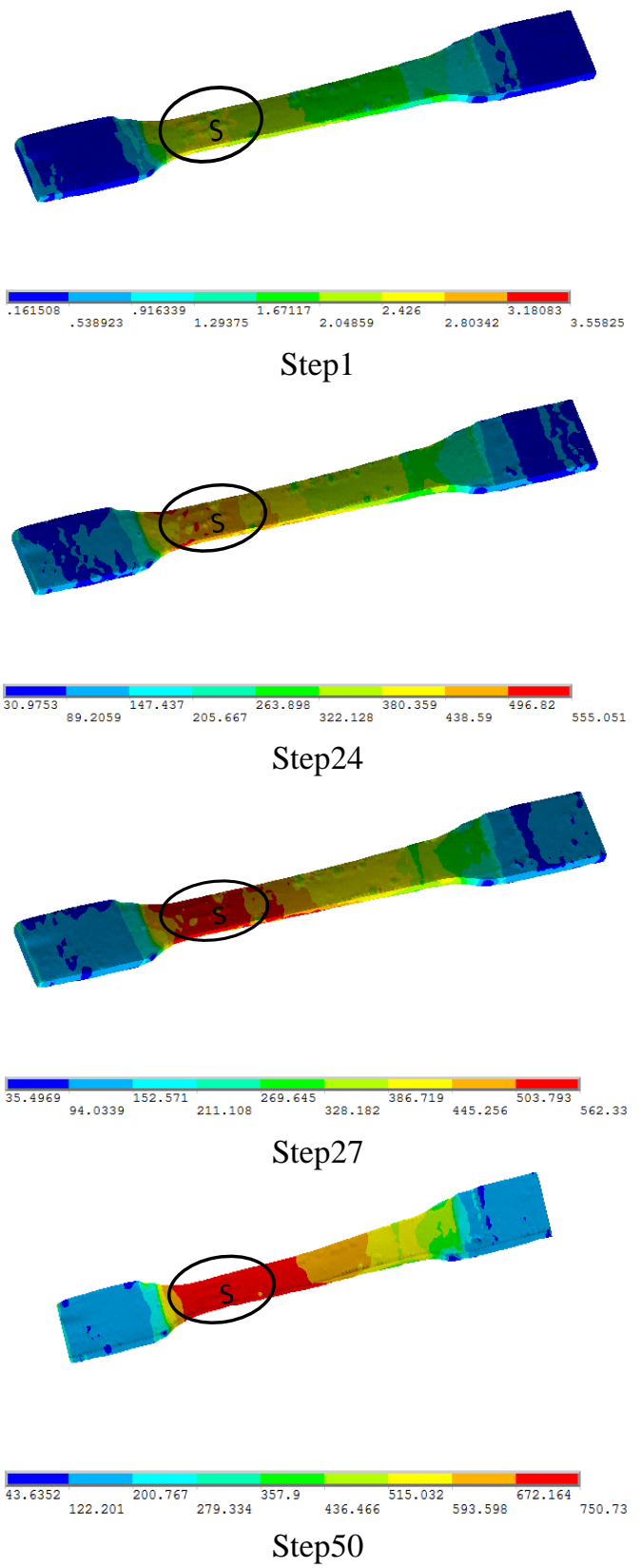

Fig. 21 Stress nephogram of specimen D20-3 at different time steps (unit: MPa)

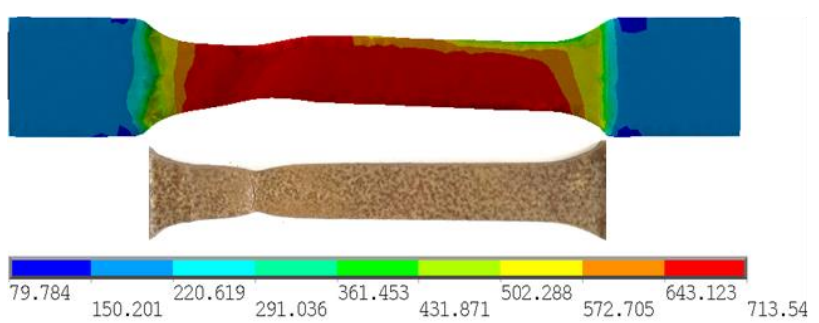

Fig. 22 Stress distribution at ultimate load

\section{Conclusions}

This study aims to investigate the mechanical properties of corroded HPS affected by corrosion. 3D scanning technology was applied on 15 specimens to determine the geometric features. Tensile tests and numerical simulations were performed to analyze the mechanical degradation behavior. The main conclusions obtained from this study can be summarized as follows:

(1) The fracture position of the corroded specimens occurs at the minimum section area location. The maximum cross-sectional loss ratio $\rho_{A}$ is reasonable to evaluate the mechanical behavior of the corroded steel 
specimens.

(2) Corrosion affects significantly the tensile failure of the HPS specimens, which changes the fracture morphology of specimens from crescent to irregular shape. The failure of the seriously corroded specimens is very brittle without obvious dimples and necking at the fracture surface.

(3) The yield and ultimate load decrease linearly as the maximum cross-sectional loss ratio increases. The relative nominal or real yield strength decreases exponentially, while the relative nominal or real ultimate strength increase in a similar parabolic way.

(4) A three-stage constitutive model of HPS specimens is proposed in this study, and a comparison between the experimental results and numerical results has been performed to verify and demonstrate the application of the proposed constitutive model of HPS specimens.

It is noted that the maximum cross-sectional loss ratio is the precondition to determine the deterioration law of mechanical parameters. In practical engineering, it can be obtained by some measuring means. As a result, the mechanical parameters of the corroded material can be calculated according to the degradation model proposed in this paper, and then the preliminary evaluation of strength and deformation of structural performance can be made.

The preceding findings are suitable for HPS specimens subjected to electrochemically accelerated corrosion, which may have some differences from the real corrosion condition. Additionally, the number of specimens is limited and further research needs to be carried out to further verify these conclusions.

\section{Acknowledgements}

This work was financially supported by the National Basic Research Program of China (No. 2015CB057701), the Guangdong Natural Science Foundation (No. 2015A030310141), the Open Fund of Hunan Province Engineering Laboratory of Bridge Structure (CSUST) (No. 16BCX11), and the Graduate Student Research Innovation Project of Hunan Province (CSUST) (No. CX2017BS04). These supports are deeply acknowledged.

\section{References}

[1] Miki C., Homma K. and Tominaga T., "High strength and high performance steels and their use in bridge structures", Journal of Constructional Steel Research, 58(1), 3-20, 2002.

[2] Shi G., Ban H.Y., Shi Y.J. and Wang Y.Q., "Engineering application and recent research progress on high strength steel structures", Industrial Construction, 42(1), 1-7, 2012. (in Chinese)

[3] Shi G., Wang M., Bai Y., Wang F., Shi Y.J. and Wang Y., "Experimental and modeling study of high-strength structural steel under cyclic loading", Engineering Structures, 37, 1-13, 2012.

[4] Wang C.S., Duan L., Wang J.M. and Li Z., "Bending behavior and ductility test of high performance steel beam based on hybrid design", China Journal of Highway and Transport, 25(2), 81-89, 2012. (in Chinese)

[5] Kayser C., Swanson J. and Linzell D., "Characterization of material properties of HPS-485W(70W) for bridge girder applications", Journal of Bridge Engineering, ASCE, 11(1), 99-108, 2006.

[6] Li G.Q., Yan X.L. and Chen S., "Experimental study on the ultimate bearing capacity of welded box-section columns using Q460 high strength steel in bending and axial compression", China Civil Engineering Journal, 45(8), 67-73, 2012. (in Chinese)

[7] Li G.Q, Wang Y.B, Chen S.W., Cui W. and Sun F.F., "Experimental study of Q460C high strength steel welded H-section and box-section columns under cyclic loading", Journal of Building Structures, 34(3), 80-86, 2013. (in Chinese)

[8] Lee H.E., Joo H.S., Choi B.H. and Moon J.H., "Evaluation of flexural ductility of negative moment region of I-girder with high strength steel”, Procedia Engineering, 14, 272-279, 2011.

[9] Kim I.T., Lee M.J., Ahn J.H. and Kainuma S., "Experimental evaluation of shear buckling behaviors and strength of locally corroded web", Journal of Constructional Steel Research, $83,75-89,2013$.

[10] Tohidi S. and Sharifi Y., "Load-carrying capacity of locally corroded steel plate girder ends using artificial neural network", Thin-Walled Structures, 100, 48-61, 2016.

[11] Khedmati M.R., Roshanali M.M. and Nouri Z.H.M.E., "Strength of steel plates with both-sides randomly distributed with corrosion wastage under uniaxial compression", Thin-Walled Structures, 49(2), 325-342, 2011.

[12] Nakai T., Matsushita H., Yamamoto N. and Arai, H., "Effect of pitting corrosion on local strength of hold frames of bulk carriers (1st report)", Marine Structure, 17(5), 403-432,
2004

[13] Beaulieu L.V., Legeron F. and Langlois S., "Compression strength of corroded steel angle members", Journal of Constructional Steel Research, 66(11), 1366-1372, 2010.

[14] Salem E.S., Flexural Strength and Ductility of Highway BridgeI-Girders Fabricated from HPS-100W Steel, Ph.D. Dissertation, Lehigh University, Bethlehem, PA, 2004.

[15] Wang Y.B., Li G.Q. and Chen S.W., "Experimental and numerical study on the behavior of axially compressed high strength steel box-columns", Engineering Structures, 58(1), 79-91, 2014.

[16] Lee C.H., Han K.H., Uang C.M., Kim D.K., Park C.H. and Kim J.H., "Flexural strength and rotation capacity of I-shaped beams fabricated from $800 \mathrm{MPa}$ steel", Journal of Structural Engineering, ASCE, 139(6), 1043-1058, 2013.

[17] Yang Y.M., Peng J.X., Zhang J.R. and Cai C.S., A New Method for Estimating the Scale of Fluctuation in Reliability Assessment of Reinforced Concrete Structures Considering Spatial Variability, Advances in Structural Engineering, 2018, DOI: $10.1177 / 1369433218760891$.

[18] Ma Y.F., Guo Z.Z., Wang L. and Zhang J.R., "Experimental investigation of corrosion effect on bond behavior between reinforcing bar and concrete", Construction and Building Materials, 152, 240-249, 2017

[19] Francois R., Khan I. and Dang V.H., "Impact of corrosion on mechanical properties of steel embedded in 27-year-old corroded reinforced concrete beams", Materials and Structures, 46(6), 899-910, 2013.

[20] Yuan Z., Fang C., Parsaeimaram M. and Yang S., "Cyclic behavior of corroded reinforced concrete bridge piers", Journal of Bridge Engineering, ASCE, 22(7), 04017020, 2017.

[21] Wang X.G., Zhang W.P., Gu X.L. and Dai H.C., "Determination of residual cross-sectional areas of corroded bars in reinforced concrete structures using easy-to-measure variables", Construction and Building Materials, 38, 846-853, 2013.

[22] An L., Ouyang P. and Zheng Y.M., "Effect of stress concentration on mechanical properties of corroded reinforcing steel bars", Journal of Southeast University (Natural Science E.) 35(6), 940-944, 2005.

[23] Stewart M.G., "Spatial variability of pitting corrosion and its influence on structura fragility and reliability of RC beams in flexure", Structural Safety, 26(4), 453-470, 2004.

[24] Malumbela G., Alexander M. and Moyo P., "Variation of steel loss and its effect on the ultimate flexural capacity of RC beams corroded and repaired under load", Construction and Building Materials, 24(6), 1051-1059, 2010.

[25] Kashani M.M., Crewe A.J. and Alexander N.A., "Use of a 3D optical measurement technique for stochastic corrosion pattern analysis of reinforcing bars subjected to accelerated corrosion", Corrosion Science, 73, 208-221, 2013.

[26] Fernandez I., Bairán J.M. and Marí A.R., "3D FEM model development from 3D optical measurement technique applied to corroded steel bars", Construction and Building Materials, 124, 519-532, 2016.

[27] Zhang W.P., Zhou B.B., Gu X.X. and Dai H.C., "Probability distribution model for cross-sectional area of corroded reinforcing steel bars", Journal of Materials in Civil Engineering, 26(5), 822-832, 2014.

[28] Standardization Administration of China, Metallic Materials-Tensile Testing at Ambient Temperature, GB/T 228-2002, Beijing, Standards Press of China, 2002. (in Chinese)

[29] Maaddawy T.A.E. and Soudki K.A., "Effectiveness of impressed current technique to simulate corrosion of steel reinforcement in concrete", Journal of Materials in Civil Engineering, ASCE, 15(1), 41-47, 2003.

[30] American Society for Testing and Materials, Standard Practice for Preparing, Cleaning, and Evaluating Corrosion Test Specimens, G1-03, West Conshohocken, PA, 2003.

[31] Motra H.B., Hildebrand J. and Dimmig-osburg A., "Assessment of strain measurement techniques to characterise mechanical properties of structural steel", Engineering Science and Technology, an International Journal, 17(4), 260-269, 2014

[32] Fernandez I., Bairán J.M. and Marí A.R., "Corrosion effects on the mechanical properties of reinforcing steel bars. fatigue and $\sigma-\varepsilon$ behavior", Construction and Building Materials, 101, 772-783, 2015.

[33] Apostolopoulos C.A., Demis S. and Papadakis V.G., "Chloride-induced corrosion of steel reinforcement-mechanical performance and pit depth analysis", Construction and Building Materials, 38, 139-146, 2013.

[34] Qin G.C., Xu S.H., Yao D.Q. and Zhang Z.X. "Study on the degradation of mechanical properties of corroded steel plates based on surface topography", Journal of Constructional Steel Research, 125, 205-217, 2016

[35] Appuhamy J.M.R.S., Kaita T., Ohga M and Fujii K., "Prediction of residual strength of corroded tensile steel plates", International Journal of Steel Structures, 11(1), 65-79, 2011.

[36] Zhang W.P., Shang D.F. and Gu X.L., "Stress-strain relationship of corroded steel bars", Journal of Tongji University (Natural Science), 34(5), 586-592, 2006. (in Chinese)

[37] Zhang W.P., Dai H.C., Gu X.L. and Wu S.N., "Effects of Corrosion Pits on Mechanical Properties of Corroded Steel Bars", 12th Biennial International Conference on Engineering, Construction, and Operations in Challenging Environments, Reston, 3504-3511, 2010.

[38] Ahmmad M.M. and Sumi Y., "Strength and deformability of corroded steel plates under quasi-static tensile load", Journal of Marine Science and Technology, 15(1), 1-15, 2010.

[39] Tang F.J., Lin Z.B., Chen G.D. and Yi W.J., "Three-dimensional corrosion pit measurement and statistical mechanical degradation analysis of deformed steel bars subjected to accelerated corrosion", Construction and Building Materials, 70, 104-117, 2014.

[40] Xu S.H., Wang H., Li A.B., Wang Y.D. and Su L., "Effects of corrosion on surface characterization and mechanical properties of butt-welded joints", Journal of Constructional Steel Research, 126, 50-62, 2016. 